\title{
A border adjustment for the EU ETS: \\ Reconciling WTO rules and capacity to tackle carbon leakage
}

\begin{abstract}
This article compares several configurations of a border adjustment (BA) to the EU ETS defined so as to maximise their WTO-compatibility, either with the GATT general regime or with Article XX, its environmental exception rule. The different BAs are assessed quantitatively using the partial equilibrium model CASE II which represents four sectors (cement, aluminium, steel and electricity) included in the EU ETS. We find that the inclusion of imports and exports would reduce world emissions more than the inclusion of imports alone, that an obligation to buy EU allowances is more compatible with WTO rules than one based on a tax, and would be better at reducing world emissions. Moreover, if the BA is based on best available technologies, more precisely on the recently defined EU product-specific benchmarks, the adjustment is only partial but carbon leakage is nevertheless significantly reduced. Lastly, we highlight a frequent misunderstanding, i.e. that a BA contributes to both carbon leakage limitation and to domestic production preservation: it would efficiently limit leakage, but a decrease in European production of GHG-intensive products is to be expected. Industries which consume cement, aluminium and steel would pay more for these GHGintensive goods with a border adjustment. Consequently, the price signal should be preserved and diffused in the rest of the economy, a key expected result of climate policy. Free allocation efficiently preserves domestic production but does not preserve and diffuse the price signal and is less efficient in limiting leakage.
\end{abstract}

\section{Keywords}

Border adjustment, carbon leakage, emission trading system, World Trade Organization. 


\section{Introduction}

Several countries are experiencing increased political pressure for some form of border adjustment (BA) to complement stringent climate policy. This would level the playing field between domestic producers and foreign producers who experience little or no constraint on their greenhouse gas (GHG) emissions. Arguments that justify such a trade measure generally refer to competitiveness concerns and/or the weakening of environmental efficiency. ${ }^{1}$ Indeed, if a firm faces higher costs in its home country, it may struggle to compete and move offshore or lose its business to offshore companies. The domestic industry will then lose market share in both domestic and foreign markets, resulting in job losses at home and an increase in GHG emissions abroad, i.e. carbon leakage.

However, as a trade measure, a BA may be contested by a World Trade Organization (WTO) member under its dispute settlement mechanism. In fact, some early observers considered a BA in complement to a domestic ETS or tax on GHG emission to be incompatible with WTO rules (see the references in Godard, 2011). But several analyses, including a recent report from UNEP and WTO (2009), have questioned this position (de Cendra, 2006; Ismer and Neuhoff, 2007; Pauwelyn, 2007; Eichenberg, 2010) and concluded that, under some conditions, such a measure may be WTOcompatible. Not all experts agree on the conditions but some common elements can be identified, thus allowing for the draft of a BA that would be compatible with WTO rules - or at least can increase the chances of it being so. Yet the design of the BA also impacts on carbon leakage mitigation. Our analysis examines this point in the context of the European Union Emission Trading Scheme (EU ETS).

The aim of the present paper is not to reach conclusions on the opportunities for implementing an EU border adjustment, but to propose a quantitative analysis of the most WTO-compatible BAs. In particular, we examine their efficiency in limiting carbon leakage, as well as their impact on the production and market shares of European firms.

The quantitative analysis is based on CASE II, a static and partial equilibrium model which represents four sectors included in the EU ETS (cement, aluminium, steel and electricity). The analysis examines the implications of different BA designs for production, prices and trade flows in each industry, as well as on the leakage-to-reduction ratio for each sector and for the whole ETS. Throughout this paper, we assume that allowances are fully auctioned. Firstly, a BA is much more difficult to justify under free allocation than under auctioning. This is a common conclusion of the literature (de Cendra, 2006; van Asselt and Biermann, 2007; Kommerskollegium, 2009). ${ }^{2}$ Secondly, with a BA,

\footnotetext{
${ }^{1}$ A third argument is to create further incentives for countries to join an international climate agreement (Cosbey, 2008).

${ }^{2}$ Free allocation still asks business to bear costs that may be significant but Genasci (2008) gives some simple examples of the difficulties to respect WTO rules with free allocation.
} 
European industry suffers less from competitive disadvantage so there is little rationale for free allocation that creates economic distortions (Matthes and Neuhoff, 2008). ${ }^{3}$

In the first part, based on the law literature, we discuss the design of a potential BA to the EU ETS. The second part presents the model and the scenarios. The third part discusses the results.

\section{How to maximize the WTO-compatibility of a BA?}

To implement a BA several elements must be defined, in particular, form (e.g. tax-based or allowances-based), coverage (e.g. imports and exports or only imports; direct and indirect emissions or only direct emissions) and adjustment base (e.g. EU or foreign average specific emissions, best available technologies, or plant specific emissions).

Based on the recent law literature, we identify points critical for WTO-compatibility. Generally, two options are examined: firstly, compatibility with the GATT general regime, and then a possible recourse to the environmental exception rule, Article $X X$, if the $B A$ has not been judged compatible with the general regime. Each option can refer to very different requirements. Moreover, we must keep in mind that WTO-compatibility depends, not only on its design, but also on the manner in which it is implemented, especially for the "Article XX" option which cannot be taken into account in our modelling.

\subsection{General regime}

Under the GATT general regime, several articles must be taken into account to avoid being found in violation of GATT rules because the import and export parts of the BA come under different articles. GATT Articles I, II and III are particularly important with respect to imports, and GATT Article XVI, as well as the 1994 Agreement on Subsidies and Countervailing Measures (SCM), to exports (Eichenberg, 2010). Specifically, Article III requires WTO members to treat foreign goods no less favourably than comparable domestic goods, while GATT Article XVI expresses general disapproval of subsidies and instructs signatories to avoid their use wherever possible (Kommerskollegium, 2009).

According to Pauwelyn (2009), carbon equalization measures on imports at the border (a border duty, allowance requirement or performance standard) may be modelled in compliance with WTO non-discrimination rules if the measure does not impose a heavier burden on imported products than on domestic products. Moreover, Kang (2010) states that "once the products at issue are found

\footnotetext{
${ }^{3}$ Due to the framework of the EU ETS as multi-period scheme with a series of direct and indirect updating provisions, free allowance allocation distorts the carbon price signal for efficient investment, operation and consumption choices.
} 
like products", taxes on imports even slightly "in excess of like domestic products will be found in violation of GATT Article III:2". This is then a crucial point to respect.

In the EU ETS, it would be simpler to ensure similar treatment between European and non-European firms by basing carbon equalization measures on allowances (Genasci, 2008; Monjon and Quirion, 2010). If the measure is based on an import tax, it would be difficult to determine the value of the tax that would result in similar treatment. The same arguments apply to exports.

The BA requires an estimation of the carbon content of imported products. While European firms included in the EU ETS are obliged to provide their emission level, a similar obligation can hardly be imposed on importers. Ismer and Neuhoff (2007) propose the use of Best Available Technology (BAT) for importers in order to ensure a similar treatment or at least a more favourable treatment of imported than European products. Yet the determination of a world BAT can be problematic (Monjon and Quirion, 2010). An easier way to define a BAT would be to use the product-specific benchmarks set in the EU ETS for industry products ${ }^{4}$. Although defined for a different purpose, i.e. to set the amount of freely allocated allowances, they are a good candidate for defining the quantity of emissions that should be imputed to imports. Moreover, if a particular exporting firm whose unitary emissions is lower than the EU benchmark can prove (through independent third-party verification) that its emissions are lower than the reference value, then it must be allowed to use this value (Pauwelyn, 2007).

According to Eichenberg (2010), the export part of a BA might be authorized by the SCM. The crucial point is that it does not advantage domestic producers with respect to Article XVI:4 (UNEP and WTO, 2009).

Calculating the amount of the BA - for both imports and exports - raises many challenging issues but addressing indirect emissions costs would add even more complexity. Indeed, the inclusion of indirect emissions costs would require a calculation of the emissions involved in producing electricity, which can be controversial: different methods used to assess the $\mathrm{CO}_{2}$ intensity of power generation (e.g. marginal vs. average) generate different results and interconnections between adjacent countries further complicate the analysis. Moreover, the cost pass-through in the electricity price must also be evaluated, since overestimating pass-through might result in an excessive adjustment (Genasci, 2008). For these reasons we do not include them in the designs we examine.

\footnotetext{
${ }^{4}$ These benchmarks are set at the average specific emissions of the $10 \%$ of the EU installations with the lowest specific emissions. Cf. European Commission (2010).
} 
Lastly, the most-favoured nation principle (Article I) requires the imposition of the BA on all WTO Members. Therefore it is not possible to exempt a group of countries because, for instance, they are engaged in an international climate agreement, or are the least developed countries.

Given the different elements relevant to the GATT general regime, we propose to test an allowancebased BA on imports and exports with an adjustment coefficient for imports based on a European benchmark. Since the benchmark is lower than both the EU and the foreign specific emission level, the adjustment is only partial. For the export part, European firms are not obliged to surrender allowances when their production is exported outside of the EU.

\subsection{Article $X X$}

If the core provision of world trade law prohibits a BA, it may still be allowed by one of the general exception provisions of Article XX. In particular, Article XX allows trade restrictions to "protect human, animal or plant life or health" (Art. XX (b)) or to ensure "the conservation of exhaustible natural resources" (Art. XX (g)). It cannot be invoked to offset competitive disadvantages for domestic industry. Wiers (2008) emphasizes that the measure should really contribute to its environmental goal. Hence the first indicator to be examined must be impact on world emissions, even more than on carbon leakage. In relation to this point, some analyses conclude that the BA must be limited to imports (Ruiz-Fabri and Reynier, 2010), while Ismer and Neuhoff (2007) and Godard (2011) conclude that the export part of the BA can also be compatible with Article XX.

Even if it is demonstrated that the measure achieves its environmental goal, its acceptance will be determined by the balance between its contribution to climate protection and its trade restrictiveness (Kommerskollegium, 2009). Article XX Chapeau must also be respected and this states that "the measures are not applied in a manner which would constitute a means of arbitrary or unjustifiable discrimination between countries where the same conditions prevail, or a disguised restriction on international trade." The objective of the chapeau is to prevent the "abuse of exceptions" in Article XX and to ensure that they are "exercised in good faith to protect interests considered as legitimate under Article XX" (Bordoff, 2009). According to Charnovitz (2007), the adjudication focus of appraisal is on how the measure is applied, rather than how it is designed. This aspect cannot be taken into account in our modelling, but the common interpretation of Article XX is that it requires that, before imposing a unilateral BA, a country should have made all efforts to reach an international agreement. The Appellate Body's interpretation of Article XX chapeau also suggests that the EU should take the initiative in negotiating with countries that might be affected by the BA. 
The BA should take into account the efforts of trading partners to abate GHG emissions ${ }^{5}$ and this may result in lower (or no) BA on imports from countries having measures comparable in effectiveness.

What to retain for our modelling? Firstly, demonstrating the environmental benefits of the BA is crucial. Secondly, there is no clear conclusion concerning the legality of the export BA. Our objective is not to settle this issue but to evaluate the environmental performances of a BA that covers both imports and exports, and one that does not cover exports. Thirdly, there is no clear conclusion concerning the adjustment base to adopt. It may be possible to use BAT emissions or average specific foreign emissions to calculate the BA on imports. We will then examine both options, i.e. an adjustment based on the EU benchmark and an adjustment based on specific foreign emissions. ${ }^{6,7}$ Finally, to avoid the BA from being considered a "disguised restriction", we examine the evolution of the market shares of European firms as an indicator for demonstrating that the BA does not have trade-restricting objectives (de Cendra, 2006).

\subsection{Which option has the most chance of compliance?}

Our objective is not to choose an option but to provide insights into the ability of different BAs to limit carbon leakage and reduce world emissions. Nevertheless, in the law literature, it is sometimes considered that the "Article XX" option has more chance of being accepted (Cosbey, 2008; Horn and Mavroidis, 2010), but Pauwelyn (2007) emphasizes that Article XX may oblige a graduation, or even exclusion of (i) countries with their own climate policies in place, and (ii) countries at a low level of development. This would considerably reduce the BA coverage since the present world is characterised by asymmetric carbon constraints rather than by a world composed of one group of countries with a climate policy and another group without. ${ }^{8}$ Nevertheless, Godard (2011) moderates this last position.

\footnotetext{
${ }^{5}$ This last point may be important for the legality of the BA. Nevertheless, serious doubts still exist about the implementation of a carbon constraint on $\mathrm{CO}_{2}$-intensive industry in the USA or in Japan. The pledges taken in the Copenhagen and Cancun Accords may lead to a mix of measures which do not really affect the production cost of these industries.

${ }^{6}$ Whichever the measure applied, importers must be permitted to demonstrate how much carbon they emitted individually and pay for allowances on that basis (Bordoff, 2009).

${ }^{7}$ An adjustment based on foreign specific emissions is problematic to evaluate because most of non-EU production installations have no obligation to declare - and thus do not know precisely - their $\mathrm{CO}_{2}$ emissions. An option is to ask importers to provide certified information on the carbon content of the products they want to import in the EU, but it is difficult to oblige importers to do so since for a small importer, the administrative burden could be high in proportion of its sales. Another option is to use the average emissions per tonne in the exporting country for every product covered by the BA, but this value could be difficult to compute, especially if the country is reluctant to participate. Consequently the practical feasibility of this scenario is not certain.

${ }^{8}$ Conversely, if Article XX is not used, it is not possible to exempt a group of countries, for instance because they are engaged in an international climate agreement, or the least developed countries, due to the GATT most favoured nation principle (cf. previous section).
} 


\section{The model and the scenarios}

CASE II is a static and partial equilibrium model which aims to evaluate the impact of different EU ETS third period (2013-2020) designs. The sectors represented - cement, aluminium, steel and electricity - share a potentially large impact on carbon pricing but have contrasting direct and indirect emissions, as well as different exposures to international competition (Hourcade et al., 2007). They represent around $75 \%$ of the emissions covered by the system (Kettner et al., 2007; MEDDTL and CDC, 2010). The model features two regions: the European Union 27 (EU) and the rest of the world $(\text { RoW })^{9}$. Although general equilibrium effects have significant implications for climate policy, they play a role in leakage through the international energy markets channel above all, but are less important for comparing anti-leakage policies (Fischer and Fox, 2009). Moreover, the competitiveness channel of leakage is a microeconomic mechanism; a partial equilibrium model is then relevant to analyse it (Quirion, 2010). Admittedly, the neglect of general equilibrium effects is a limitation because these two leakage channels are, to some extent, interrelated (cf. Kuik and Hofkes, 2010), and because we cannot analyse whether the different policy scenarios allow the carbon price signal to travel down the production chain to the consumer. However, general equilibrium models suffer from a higher sectoral aggregation than our model. In particular, they do not isolate cement or aluminium.

When a climate policy is implemented in the EU, domestic firms incur three types of additional cost:

- Abatement cost, based on marginal abatement cost curves (MACCs) taken from the POLES model for the year 2020 at the aggregated EU27 level. In POLES, MACCs are available for $\mathrm{CO}_{2}$ energy emissions from, among others, non-metallic minerals, steel and electricity sectors. MACCs give the decrease in emissions for each $\mathrm{CO}_{2}$ price. Abatement costs are incorporated into the model as variable costs as in Fischer and Fox (2009). POLES does not include a MACC for the aluminium sector so we use data from the Energy Modelling Forum EMF-21 project on multi-gas mitigation (Weyant et al., 2006).

- Purchase of allowances, if needed.

- Increase in electricity price: the marginal production cost of cement, aluminium and steel increases when the electricity price rises. We assume a cost pass-through of $100 \%$ in the power sector, whatever the policy scenario modelled. The electricity price rises by the sum of the abatement cost and the purchase costs of allowances.

Due to space constraints, the details of the model are presented in an Appendix available online.

\footnotetext{
${ }^{9}$ Because the model aggregates all foreign countries into one RoW region, we cannot assess a border adjustment based on country-of-origin specific allowance obligations, which could reduce leakage further.
} 
Compared to the version of the model used in Monjon and Quirion (2011), the main difference is that economic growth assumptions have been updated to account for the economic downturn. GDP growth projections are taken from IEA (2010). Moreover, the scenarios tested differ significantly as explained below. Finally, we model the EU ETS in 2020, hence assuming a cap at 21\% below 2005 emissions, but we assume that credits from CDM and JI will amount to $6 \%$ of the cap in $2020^{10}$ so the cap is set at $15 \%(21 \%-6 \%)$ below 2005 emissions.

Scenario $\mathbf{0}$ is a no-policy scenario which assumes no ETS.

Scenario 1 features full auctioning of allowances without rebating the auction revenues to the firms covered by the ETS and without any anti-leakage provision.

In Scenario 2, allocation is simulated in a way that is as close as possible to the actual allowance allocation in the EU ETS. Firms in the cement, steel and aluminium sectors that are exposed to leakage, receive free allowances, while firms in the power generation sector do not. The amount of free allocation is calculated as the product-specific benchmark (in $\mathrm{tCO}_{2} \mathrm{e} /$ tonne produced) multiplied by the production of the sector in 2005 . Then, if necessary, a reduction factor is applied if the sum of the allowances in the cement, aluminium and steel sectors is above $85 \%$ of their 2005 emissions. Moreover, new firms entering the market receive allowances, under the "new entrant reserve" provisions, while firms exiting the market do not receive allowances because of the "closure rules". Unlike output-based allocation, the allowance a firm receives is not proportional to its current output level.

Scenarios 0 to 2 are reference situations against which the following scenarios, with BA, can be compared. In scenarios 3 to 6 , we define the designs identified in the first section.

Scenario 3 assumes auctioning with a border-adjustment both on imports and exports. As in Monjon and Quirion (2011), we simulate a "tax-based" border adjustment to compare its performance with that of an "allowance-based" BA: importers have to pay a carbon tax and exporters receive a rebate. Consequently, the impact on the allowance market is less direct than with an "allowance-based" BA under which importers are obliged to buy some allowances. The import part is set at the level of the $\mathrm{CO}_{2}$ price on the EU ETS market multiplied by the EU product-specific benchmark. The export part is based on the EU average specific emissions.

In scenarios 4 to 6 , we simulate an allowance-based adjustment: importers have to buy allowances while exporters are partly exempted; this impacts the demand for, and hence the price of, allowances.

\footnotetext{
${ }^{10}$ Over 2008-2020, the limit of credits from CDM and $\mathrm{JI}$ in the EU ETS is set at $1.68 \mathrm{Gt} \mathrm{CO}_{2} \mathrm{e}$, hence $6 \%$ of the cap (Turner, 2010). We assume that this limit will be binding and that credits will be used homogenously over the period.
} 
Scenario 4 differs from scenario 3 in that it is allowance-based, as explained above. Compared to scenarios 1 to 3, the supply of allowances is adjusted to the new group of emissions covered, i.e., the fact that importers now have to buy allowances but exporters do not (see Figure 1). More precisely, the reduction factor of 15\% now applies to the 2005 emissions of EU ETS installations plus emissions from imports, minus emissions from exports. With this scheme, the cost to European firms rises only by the electricity price increase when production is exported. Moreover, we suppose that the constraint imposed on importers does not encourage them to reduce their specific emissions.

Scenario $\mathbf{5}$ is also allowance-based but the adjustment covers only imports. Consistently, the reduction factor of 15\% is now applied to the 2005 emissions of EU ETS installations plus the emissions from imports (see Figure 1).

Finally, scenario 6 is similar to the previous scenario except that the adjustment on imports is set at the level of the $\mathrm{CO}_{2}$ price on the EU ETS market multiplied by the average specific emissions in the rest of the world (see Figure 1).

Figure 1 - Different emission coverage and caps of the EU ETS in 2020

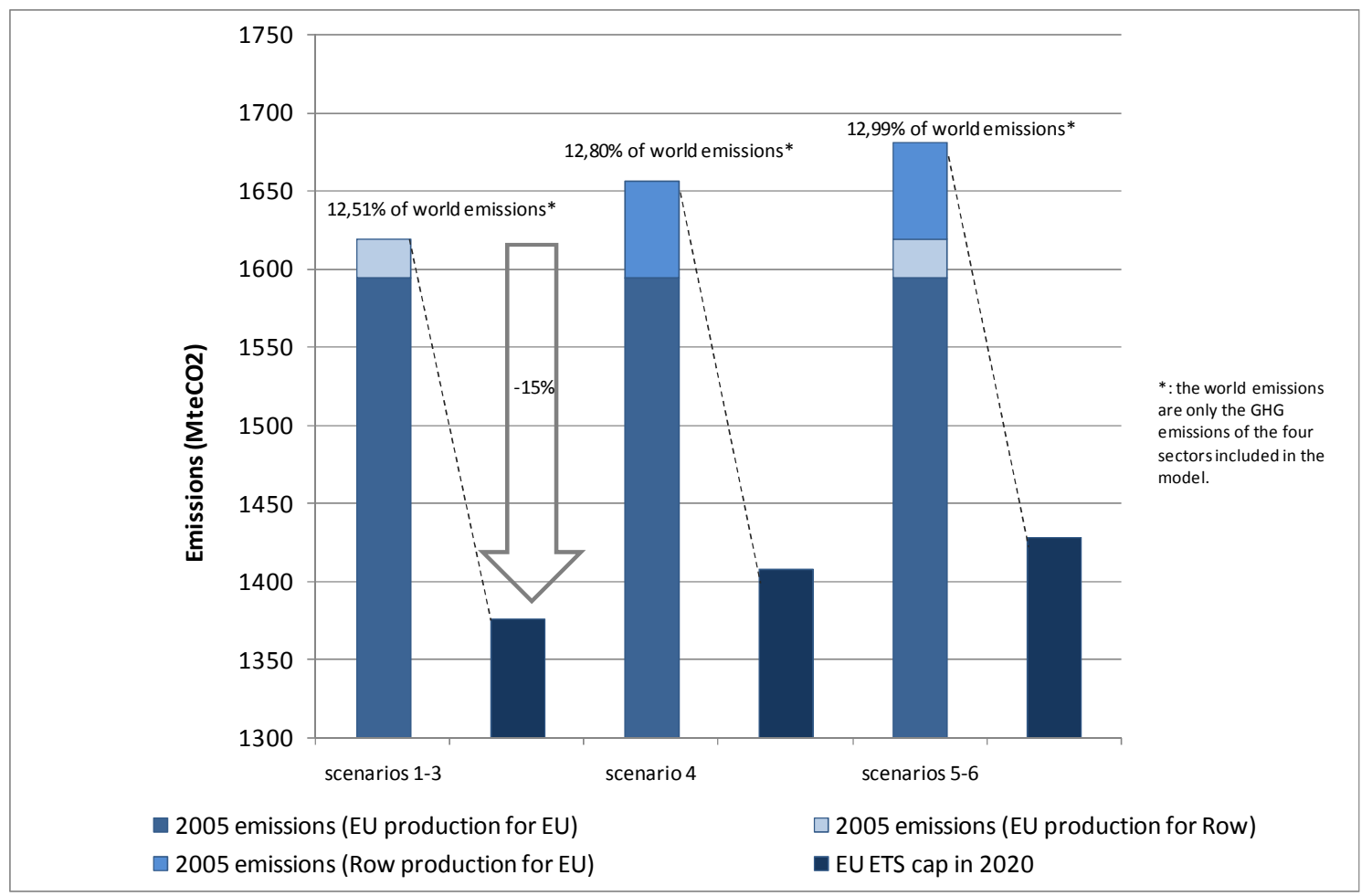




\section{Results}

\section{1. $\mathrm{CO}_{2}$ price}

Since we compare policy scenarios for a given emission reduction target but not for a given $\mathrm{CO}_{2}$ price, the variation of the latter across scenarios is worth looking at. As shown in Figure 2, the $\mathrm{CO}_{2}$ price in 2020 is around $€ 20 / t$ and is consistent with current forecasts for a target of $-21 \%$ in 2020 . It is highest with free allocation for the following reason: free allocation is economically a subsidy that a firm receives, regardless of its production level, as long as it remains in activity; ${ }^{11}$ this encourages new firms to enter the market; competition "à la Cournot" is increased, so decreasing the price on the EU market and raising quantities sold. ${ }^{12}$ This increases the demand for allowances, hence the $\mathrm{CO}_{2}$ price, which in turn reduces specific emissions.

With border adjustments, the price is higher than in Auction because the border adjustment limits the substitution of foreign production for domestic production (which is a way of reducing $\mathrm{CO}_{2}$ emissions in the EU). Thus, to prevent aggregate emissions exceeding the cap, lower specific emissions must be achieved which requires a higher price signal. Among the scenarios with a border adjustment, the price is higher in allowance-based scenarios because the model supposes that adjustment on imports is not based on the specific emissions of the plant used to produce each good, but on the EU benchmark or on the average specific emissions in the RoW. In both cases, the adjustment is exogenous for a firm which exports into the EU; hence these firms have no incentive to reduce their own specific emissions. For aggregate emissions not to excess the cap, this must be compensated by lower specific emissions in the $\mathrm{EU}$, that is, the $\mathrm{CO}_{2}$ price must be higher.

\footnotetext{
${ }^{11}$ In the EU ETS, a firm must emit more than a minimum threshold to receive its allocation (European Commission, 2010). In the model, all the firms of the same sector are symmetric and then produce the same quantity, which is higher than these thresholds in all scenarios.

${ }^{12}$ The pricing behaviour of the firms is different in the EU markets and in foreign markets. Indeed, in foreign markets, the competition increases less since EU firms have only a small market share.
} 
Figure $2-\mathrm{CO}_{2}$ price ( $€$ /allowance) and public revenues (billion $€$ )

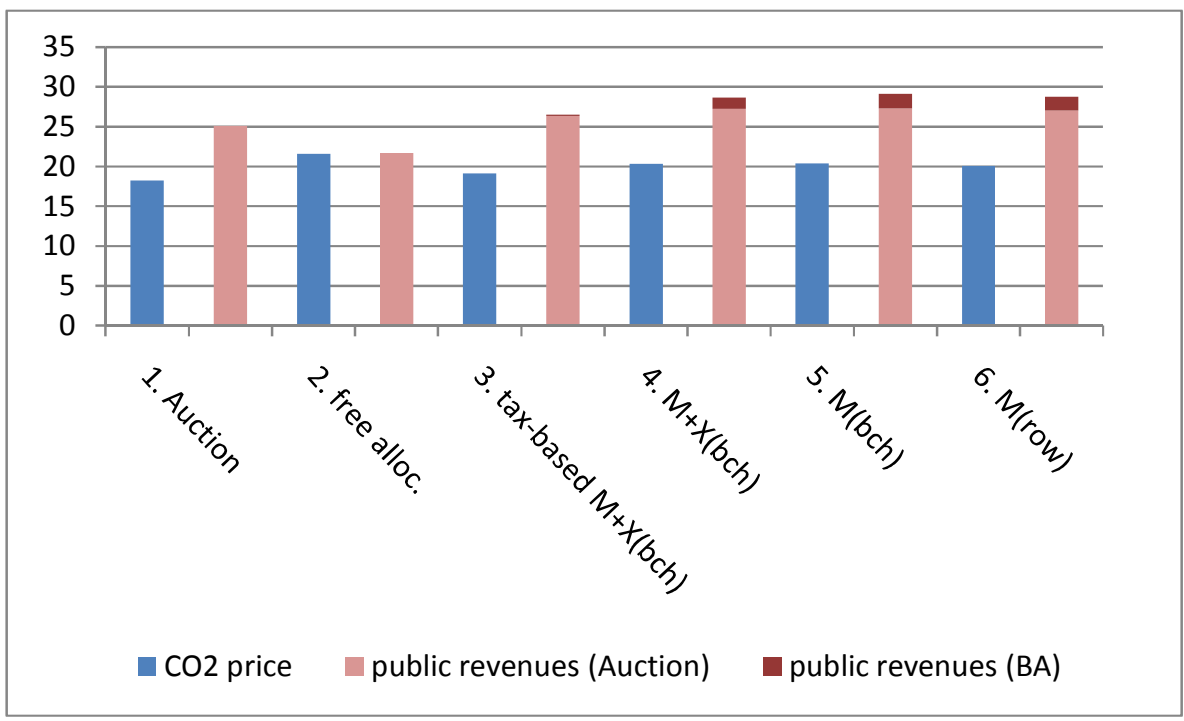

\subsection{Public revenues}

In all the scenarios, public revenues raised by selling allowances to the sectors covered by the model are between $€ 20$ and $€ 30$ billion in 2020. Free allocation gives the lowest amount which is, however, not so far from that generated in the other scenarios. The reasons are that power generation firms, which account for a majority of emissions, still have to buy allowances, and they buy them at a higher price. Public revenues are higher with a border adjustment, above all when the BA is allowancebased. The reason is a higher $\mathrm{CO}_{2}$ price and, for scenarios 4-6, a bigger number of allowances sold (see Figure 1). The latter is true even if the adjustment concerns both imports and exports because emissions from the latter are lower than emissions from imports.

The extra public revenues under the scenarios with a border adjustment (around $+€ 0.2-2$ billion, most of which are due to the increase in the $\mathrm{CO}_{2}$ price, as can be seen in Figure 2) would, of course, be welcome since most EU governments are trying to reduce public deficits. However, these revenues could also be used for climate change mitigation and/or adaptation in developing countries to facilitate an international agreement on climate change, as highlighted by Godard (2011). It would also demonstrate the "good faith" of the EU, which is an important point relative to Article XX.

For scenarios 3-6, Table 1 shows the increase in unitary production costs for European firms and for imports from the rest of the world to the EU under a BA. Neither the general regime, nor Article XX requires a comparison of the increase in costs for home and foreign products; the general regime just requires that the regulatory treatment of imported goods is no less favourable in practice than that 
for domestic products. Nevertheless, it is interesting to use our model to examine how European and foreign costs evolve in the different sectors and for each scenario.

Table 1 - Increase in unitary production cost of EU and RoW firms in scenarios 3-6 ( $€ /$ tonne of product)

\begin{tabular}{|l|c|c|c|c|}
\hline & 3. tax-based $\mathbf{M + X ( b c h )}$ & $\mathbf{4 .} \mathbf{M + X}$ (bch) & 5. $\mathbf{M}(\mathbf{b c h})$ & $\mathbf{6 .} \mathbf{M ( R o W )}$ \\
\hline EU cement & 14.1 & 14.8 & 14.9 & 14.7 \\
\hline RoW cement & 12.0 & 12.7 & 12.8 & 12.5 \\
\hline EU steel & 20.1 & 21.3 & 21.4 & 21.1 \\
\hline RoW steel & 19.6 & 20.8 & 20.8 & 34.8 \\
\hline EU aluminium & 128.6 & 136.4 & 136.7 & 134.9 \\
\hline RoW aluminium & 37.3 & 39.6 & 39.7 & 58.3 \\
\hline
\end{tabular}

The cost increase for European firms is systematically higher than for foreign firms, except when the BA import part is based on the average specific emissions of the rest of the world where it is much higher for steel. In the aluminium sector, the cost increase for European firms is much higher than for foreign firms because the main part of this increase comes from indirect emissions not included in the BA.

Figure 3 displays the change in world emissions from the cement, aluminium, steel and electricity sectors compared to the no-policy scenario and the leakage-to-reduction ratio, i.e. the increase in RoW emissions divided by the decrease in $\mathrm{EU}$ emissions. ${ }^{13} \mathrm{EU}$ emissions are constructed to be the same in the first three scenarios. Emissions in the rest of the world increase in all scenarios, though by a small amount: the leakage-to-reduction ratio is always below $11 \%$. Compared to the Auction scenario, leakage is only slightly reduced by free allocation but is at least halved by border adjustments. The most efficient adjustments for reducing leakage are those that cover both exports and imports, followed by scenario 5 which uses RoW average specific emissions rather than the EU benchmark. We find the same ranking in terms of world emissions reductions, except for the taxbased BA which is less efficient in this respect than all allowance-based BAs.

\footnotetext{
${ }^{13}$ The variations are calculated between a scenario with the climate policy and a scenario without, and include emissions from the power sector.
} 
Figure 3 - Changes in emissions compared to no-policy scenario

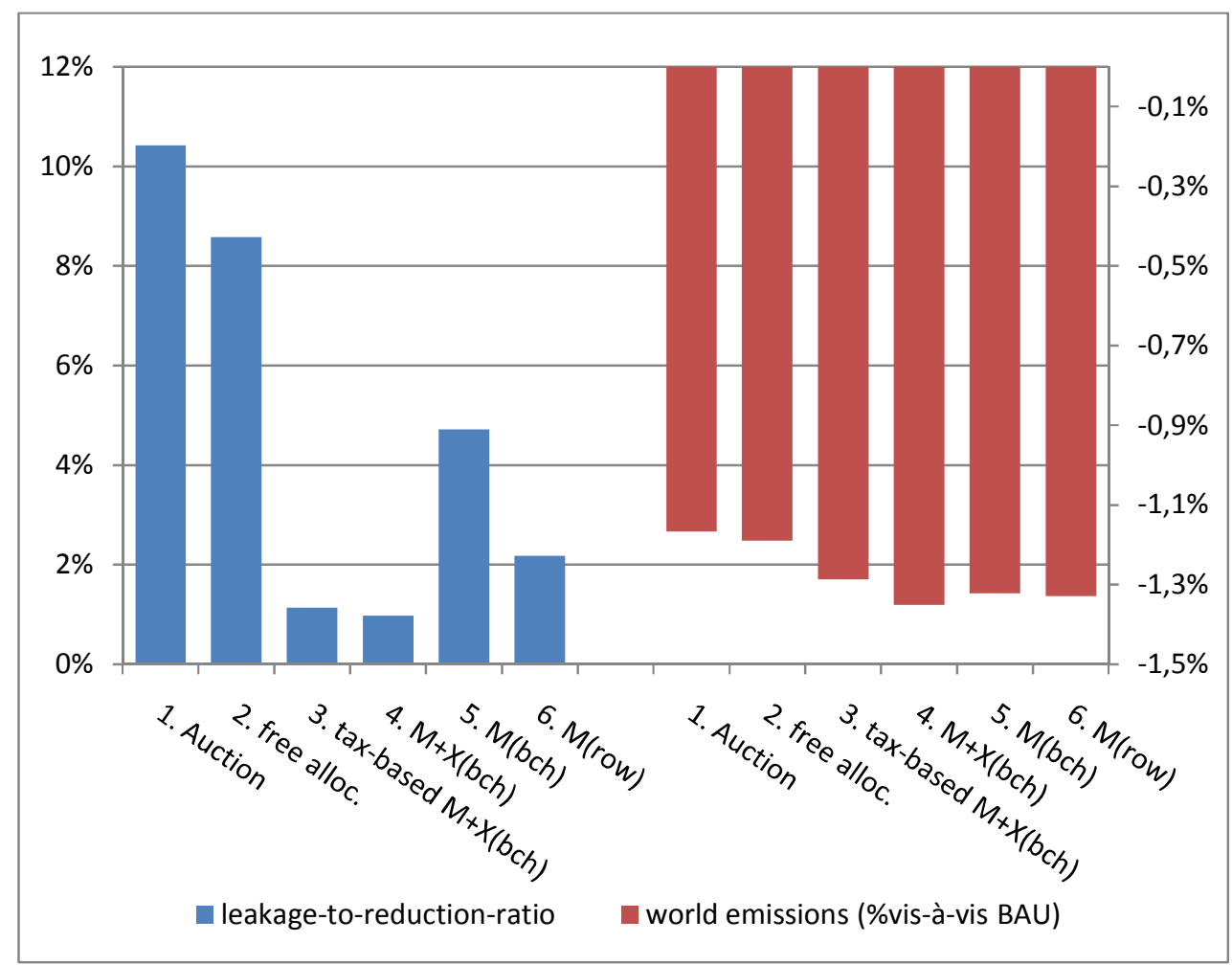

An important conclusion is that all BA scenarios reduce world emissions more than the Auction scenario. This provides a clear environmental justification for the mechanism, crucial for WTOcompatibility under Article XX.

The comparison of scenarios 3 and 4 shows that the allowance-based BA is more efficient in limiting leakage, and even more in decreasing world emissions, so an allowance-based BA is preferable to a tax-based one, both for WTO-compatibility and for environmental objectives. When the BA is applied only to imports, its environmental performance is better if the adjustment base is the average specific emissions of the rest of the world, but the WTO-compatibility of this option could be difficult. Another interesting insight from this modelling exercise is that the decrease in world emissions is higher when exports are included in the adjustment. This result is due to the fact that EU specific emissions are lower than those of the rest of the world, mainly because the $\mathrm{EU}$ industry pays a $\mathrm{CO}_{2}$ price.

For a border adjustment to be WTO-compatible and acceptable to trade partners, it should not constitute arbitrary discrimination or disguised trade restriction (see Section 1). It may be argued that, as long as a foreign firm does not pay a higher $\mathrm{CO}_{2}$ price than a European firm with the same 
specific emissions, a border adjustment does not constitute an arbitrary discrimination. Yet, if foreign producers can show that they lose market shares due to EU climate policy, they may use this argument in a possible WTO case, or may be more likely to engage in trade retaliations. For this reason, we present in Figure 4 the market shares of EU producers on the world market, i.e. the sum of the EU and RoW markets. In all the scenarios with a climate policy, the market shares of the EU are reduced compared to the no-policy scenario. Besides, the differences among scenarios 3 to 6 are very small. This result suggests that, whichever the design of the $B A$, there is no disguised restriction of trade. Note that the EU market share is lower with border adjustments than with free allocation, although, as we have seen, the latter is less efficient at reducing leakage. The explanation is a composition effect: the size of the EU market (on which the EU market share is naturally higher) is less reduced with free allocation, since the product price increase is lower (see Figure 6).

\section{Figure 4 - Variations of EU market shares on the world market compared to the no-policy scenario, in percentage points}

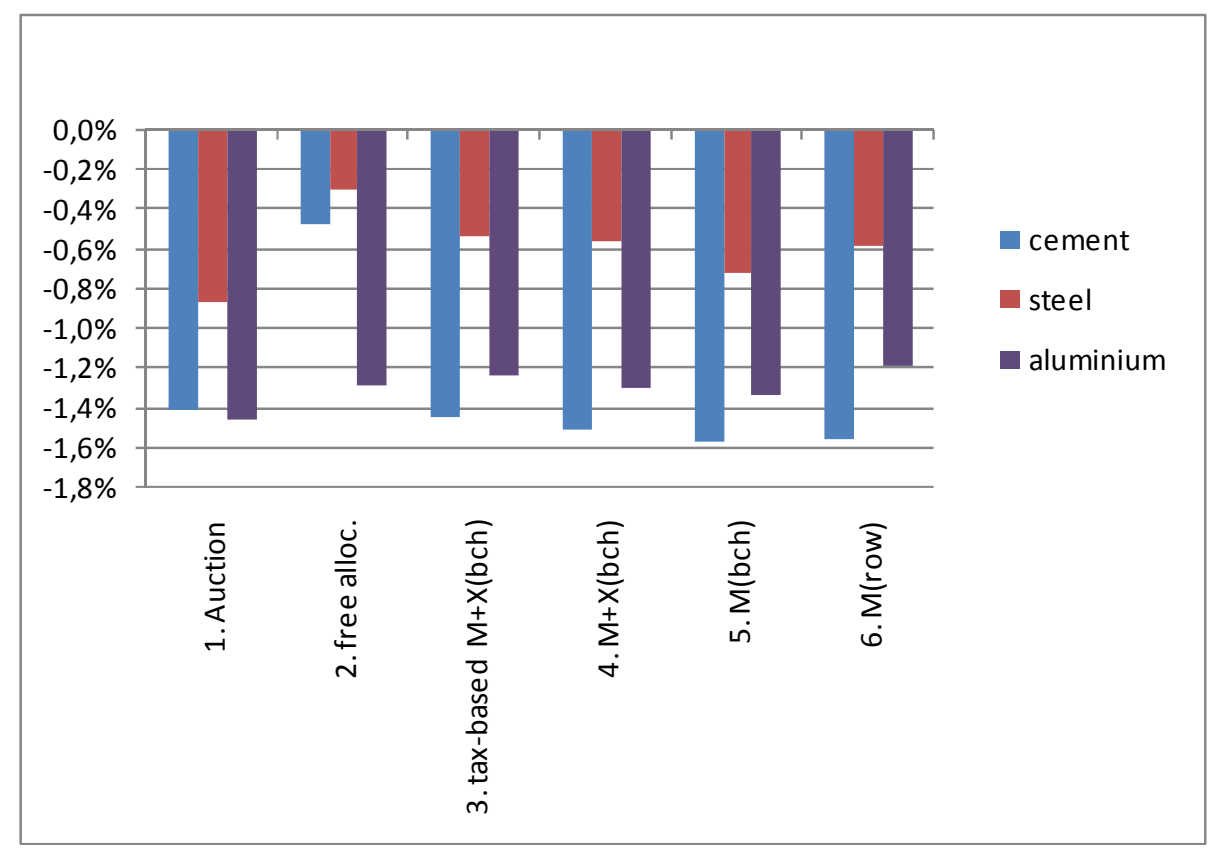

While a border adjustment is more efficient than free allocation in reducing carbon leakage, a higher production decrease in GHG-intensive sectors is to be expected (Figure 5). The border adjustment scenarios that we simulate do not shelter aluminium significantly because indirect emissions, which are higher than direct emissions, are not included. For cement, the border adjustment mitigates the substitution of imports for European production (and European exports by foreign production when 
the $\mathrm{BA}$ has an export part), but it raises the $\mathrm{CO}_{2}$ price, reduces the European demand for cement and hence, EU production for the domestic market. There is also a decrease in European steel production, although to a lesser extent: border adjustments mitigate production losses by one third at most in scenario 3 . Steel is more open to international trade but has lower $\mathrm{CO}_{2} /$ value added ratio than cement. Among the scenarios with a border adjustment covering both imports and exports, the one based on allowances features a slightly higher production loss than the one based on a border tax.

Figure 5 - Changes in EU production compared to no-policy scenario

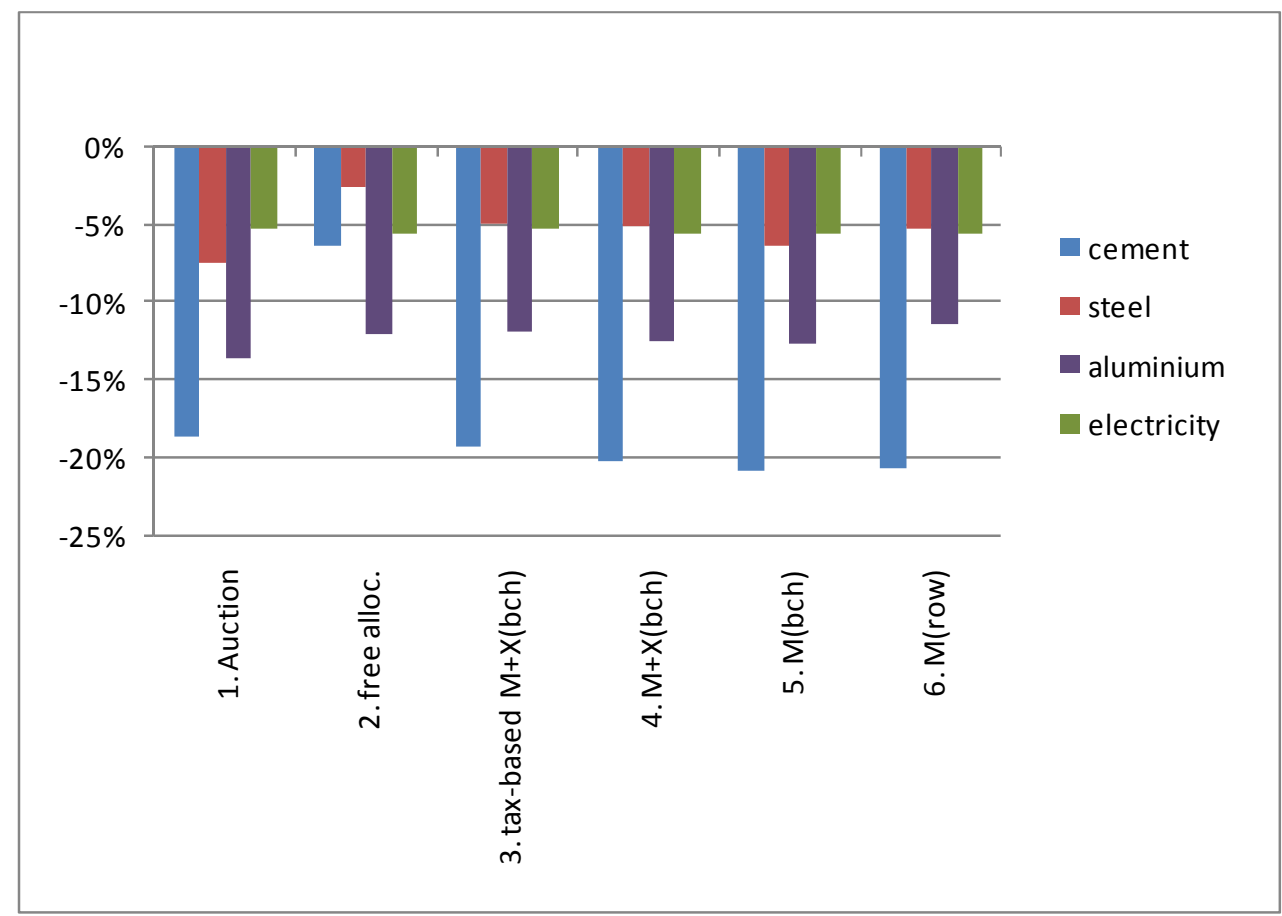

Our results highlight a frequent misunderstanding. It is often thought that one instrument, for instance a BA, can contribute both to carbon leakage limitation and to domestic production preservation. The results presented in Figures 4 and 5 lead to a different conclusion: correctly defined, a BA would perform well in limiting carbon leakage but would not prevent a significant decrease in European production. Indeed the $\mathrm{BA}$ increases the price of $\mathrm{CO}_{2}$-intensive goods in the $\mathrm{EU}$, as we can see in Figure 6, because European firms carry a $\mathrm{CO}_{2}$ price and, in addition, imports now have to pay a $\mathrm{CO}_{2}$ price. Hence, industries which consume cement, aluminium and steel, such as the construction and automobile sectors, would pay more for these $\mathrm{CO}_{2}$-intensive goods with a border 
adjustment, leading to a decrease in European demand. ${ }^{14}$ Consequently, the price signal is diffused in the rest of the economy, a key expected result of climate policy: cost-efficient abatement requires GHG-intensive goods to be replaced by cleaner goods, e.g. in buildings, wood would replace cement and stee $\left.\right|^{15}$. Free allocation in scenario 2 would limit the increase in these product prices, hence the European production decrease. However, it performs poorly in limiting carbon leakage, and would prevent much of the above-mentioned substitution.

\section{Figure 6 -Changes in the price index in the EU compared to no-policy scenario}

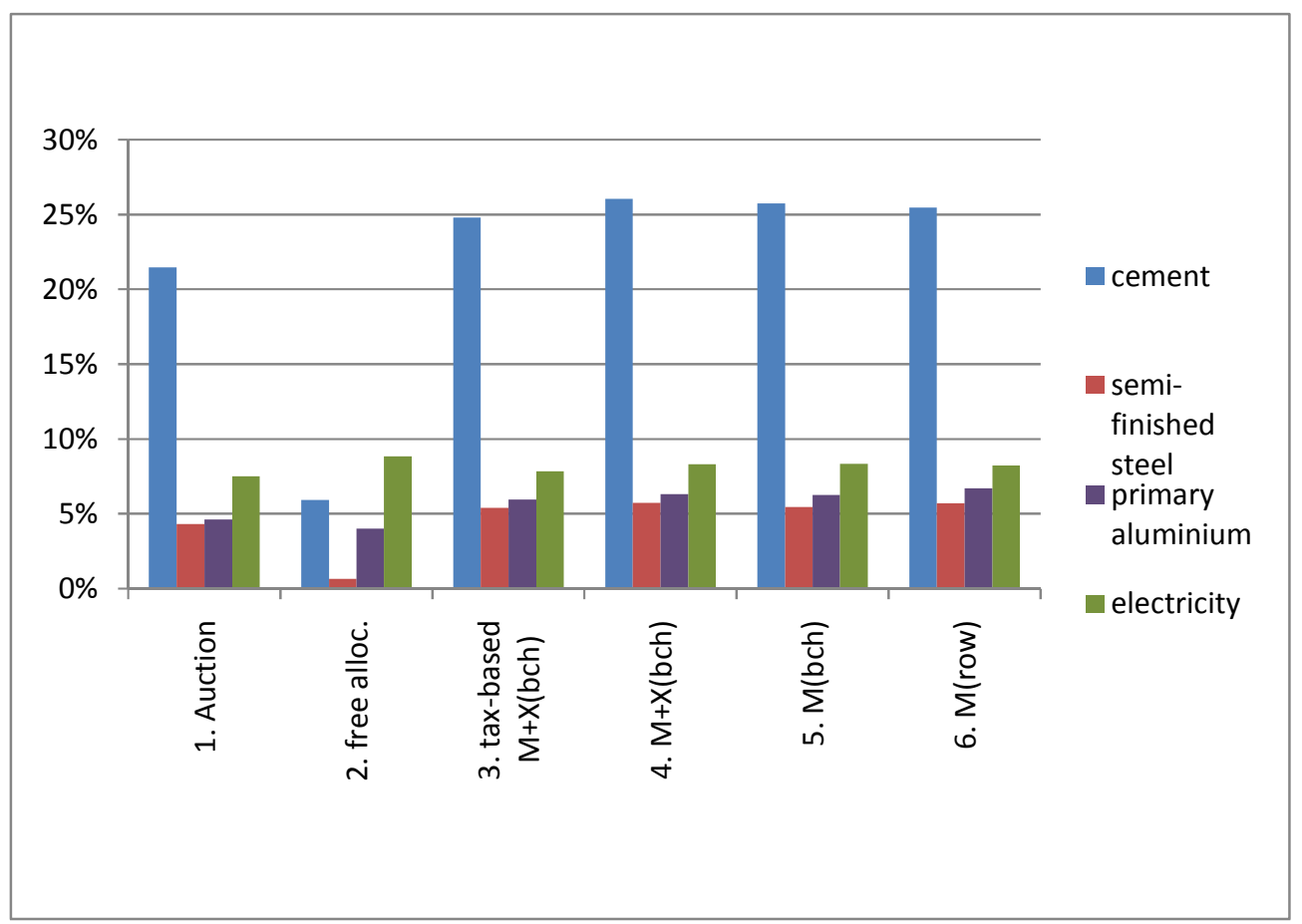

\section{Conclusions}

We have analysed different design options for a border adjustment to the EU ETS which have the best chance of being WTO-compatible. Simulations with the CASE II model indicate that all the tested

\footnotetext{
${ }^{14}$ The model does not allow taking into account the climate policy implemented in the rest of the economy. For instance, building retrofitting would moderate the decrease in cement demand.

${ }^{15}$ However, in some downstream industries, the cost increase would be weak. For example, according to ADEME (2007), the emissions related to the use of steel and aluminium in a car of 1 tonne is around 1.6 tonne of $\mathrm{CO}_{2}$. If we suppose a $\mathrm{CO}_{2}$ price of around $20 €$ and if we assume that the cost pass-through is complete in the electricity, steel and aluminium sectors, the cost increase to produce a car would be around $30-35 €$.
} 
options efficiently reduce carbon leakage to at least half that in a scenario with full auctioning and no border adjustment. Public revenues are also higher with border adjustment.

However, border adjustments lead to a production decline in EU GHG-intensive sectors, due mainly to a decrease in European consumption and not to a reduction in EU market shares. With a BA, the price signal is preserved and is diffused in the rest of the economy, a key expected result of climate policy. Nevertheless, the decrease in European production would harm some politically influential industrial sectors and constitute a political hurdle to the implementation of a BA.

Among the various options that we have tested, some are more environmentally efficient than others. Firstly, an allowance-based adjustment, which obliges importers to buy and surrender allowances, reduces world emissions more. Secondly, an adjustment on both exports and imports reduces world emissions more than an adjustment on imports alone. Finally, although an import adjustment tackles leakage more efficiently if it is based on specific emissions in the rest of the world rather than on EU specific emissions, this option is less likely to be WTO-compatible.

To sum up, the border adjustment used in scenario 4, i.e. allowance-based, covering both imports and exports and using EU product-specific benchmarks, is the most efficient in reducing world emissions and in limiting carbon leakage. Moreover, it is among the options most likely to be accepted by a WTO dispute settlement panel. Hence, if the EU wants to complement the ETS by a border adjustment (a question which goes beyond the present article), this option seems to be the most attractive.

\section{Acknowledgements}

For their very helpful comments which helped to improve the article considerably, we thank three anonymous referees. 


\section{References}

ADEME, 2007. Guide des facteurs d'émissions, Bilan Carbone ${ }^{\circledR}$ Entreprises et collectivités locales. Available at:

http://ww2.ademe.fr/servlet/getBin?name=CD6902D1AAFD8740470C44C136A32C451169215 062423.pdf

van Asselt, H. and F. Biermann, 2007. European emissions trading and the international competitiveness of energy-intensive industries: A legal and political evaluation of possible supporting measures", Energy Policy 35, 497-506.

Bordoff J., 2009. International Trade Law and the Economics of Climate Policy: Evaluating the Legality And Effectiveness of Proposals to Address Competitiveness and Leakage Concerns, in Climate Change, Trade, and Competitiveness: Is a Collision Inevitable? Edited by I. Sorkin and L. Brainard, Washington DC: Brookings Institution Press.

Cendra, J. de, 2006. Can Emission Trading Schemes be Coupled with Border Tax Adjustments? An Analysis vis-à-vis WTO Law. Review of European Community and International Environmental Law, 15(2), 131-145.

Charnovitz S., 2007. Trade and the Environment in the WTO, Journal of International Economic Law, Vol. 10, September.

Cosbey A. (Ed.), 2008. Trade and Climate Change: Issues in Perspective, Winnipeg: International Institute for Sustainable Development.

Eichenberg M.B., 2010. Greenhouse Gas Regulation and Border Tax Adjustments: The Carrot and the Stick, Golden Gate University Environmental Law Journal, Vol. 3, Issue 2 Pacific Region Edition.

European Commission, 2010.Draft Commission decision determining transitional Union-wide rules for the harmonised free allocation of emission allowances pursuant to Article 10a of Directive 2003/87/EC.

http://ec.europa.eu/clima/documentation/ets/docs/decision_benchmarking_15_dec_en.pdf

Fischer, C. and A. K. Fox, 2009. Comparing Policies to Combat Emissions Leakage: Border Tax Adjustments versus Rebates. Discussion Paper 09-02, Resources for the Future, Washington.

Genasci, M., 2008. Border tax adjustments and emissions trading: the implications of international trade law for policy design, Carbon and Climate Law Review, 2(1): 33-42

Godard, O.,2011. Intégrité environnementale des politiques climatiques et ajustement aux frontières : les enjeux pour l'Union européenne. In O. Godard et J.-P. Ponssard (eds.) Economie du climat : pistes pour l'après-Copenhague, Presses de l'Ecole Polytechnique, Palaiseau, France.

Horn H. and P.C. Mavroidis, 2010. Border Carbon Adjustments and the WTO, ENWINED (Environment and Trade in a World of Interdependence) project, working paper.

Hourcade, J.-C., D. Demailly, K. Neuhoff and M. Sato, 2008. Differentiation and Dynamics of EU ETS Industrial Competitiveness Impacts. Climate Strategies, available at www.climate-strategies.org.

IEA (International Energy Agency), 2010. World Energy Outlook.

Ismer, R. and K. Neuhoff, 2007. Border tax adjustment: a feasible way to support stringent emission trading. European Journal of Law and Economics, 24: 137-164.

Kang S., 2010. Carbon border tax adjustment from WTO point of view, Second Biennial Global Conference, Working Paper 2010/08. 
Kettner C., Köppl A., Schleicher S., Thenius G., 2007. Stringency and Distribution in the EU Emissions Trading Scheme - The 2005 Evidence. WIFO, Vienna, February.

Kommerskollegium, 2009. Climate Measures and Trade: Legal and economic aspects of border carbon adjustment, National Board of Trade.

Kuik, O. and M. Hofkes, 2010. Border adjustment for European emissions trading: competitiveness and carbon leakage. Energy Policy, 38, 1741-1748.

Matthes, F. and K. Neuhoff, 2008. The Role of Auctions for Emissions Trading, Climate Strategies report.

MEDDTL and CDC (Ministère de l'Ecologie, du Développement durable, des Transports et du Logement and Caisse des Dépots et Consignations), 2010. Chiffres clés du climat: France et Monde, Repères, Édition 2010

Monjon, S. and P. Quirion, 2010. How to design a border adjustment for the European Union Emissions Trading System?, Energy Policy, 38(9): 5199-5207

Monjon, S. and P. Quirion, 2011. Addressing leakage in the EU ETS: Border adjustment or output-based allocation? Ecological Economics, forthcoming, doi:10.1016/j.ecolecon.2011.04.020

Pauwelyn, J., 2007. U.S. Federal Climate Policy and Competitiveness Concerns: The Limits and Options of International Trade Law, Working Paper 07-02, Nicholas Institute for Environmental Policy Solutions, Duke University, Durham, N.C., April.

Pauwelyn J., 2009. Testimony Before the Subcommittee on Trade of the House Committee on Ways and Means, March 24, 2009

Quirion, P., Climate Change Policies, Competitiveness and Leakage. in Cerdá, E. and Labandeira, X. (eds.), 2010. Climate Change Policies: Global Challenges and Future Prospects. Edward Elgar Publishing, Cheltenham

Ruiz-Fabri H. and A. Reynier, 2010. Etude du mécanisme d'inclusion carbone à la lumière des règles de l'organisation mondiale du commerce, Centre d'Etude et de Recherche en Droit International, Université Paris I, Paris.

Turner, G., 2010. EU ETS Travelling Roadshow. Prague, 14 September. Bloomberg New Energy Finance.

UNEP and WTO, 2009., Trade and Climate Change, World Trade Organization, Geneva.

Weyant, J. P., F. C. de la Chesnaye and G. J. Blanford (eds), 2006. Multi-Greenhouse Gas Mitigation and Climate Policy Special Issue. The Energy Journal.

Wiers, J., 2008. French Ideas on Climate and Trade Policies", Carbon and Climate Law Review 2:1, 18-32. 


\section{Appendix. Model description}

\section{(to be provided on the internet as Supplementary Material)}

CASE II is a static and partial equilibrium model, which represents four sectors: cement, aluminium, steel and electricity (hence the name CASE). ${ }^{16}$ These sectors represent around $75 \%$ of the emissions covered by the EU ETS. All sectors are linked through the $\mathrm{CO}_{2}$ market and through the electricity market (Figure 1). ${ }^{17}$

Figure A.1 - Structure of the model

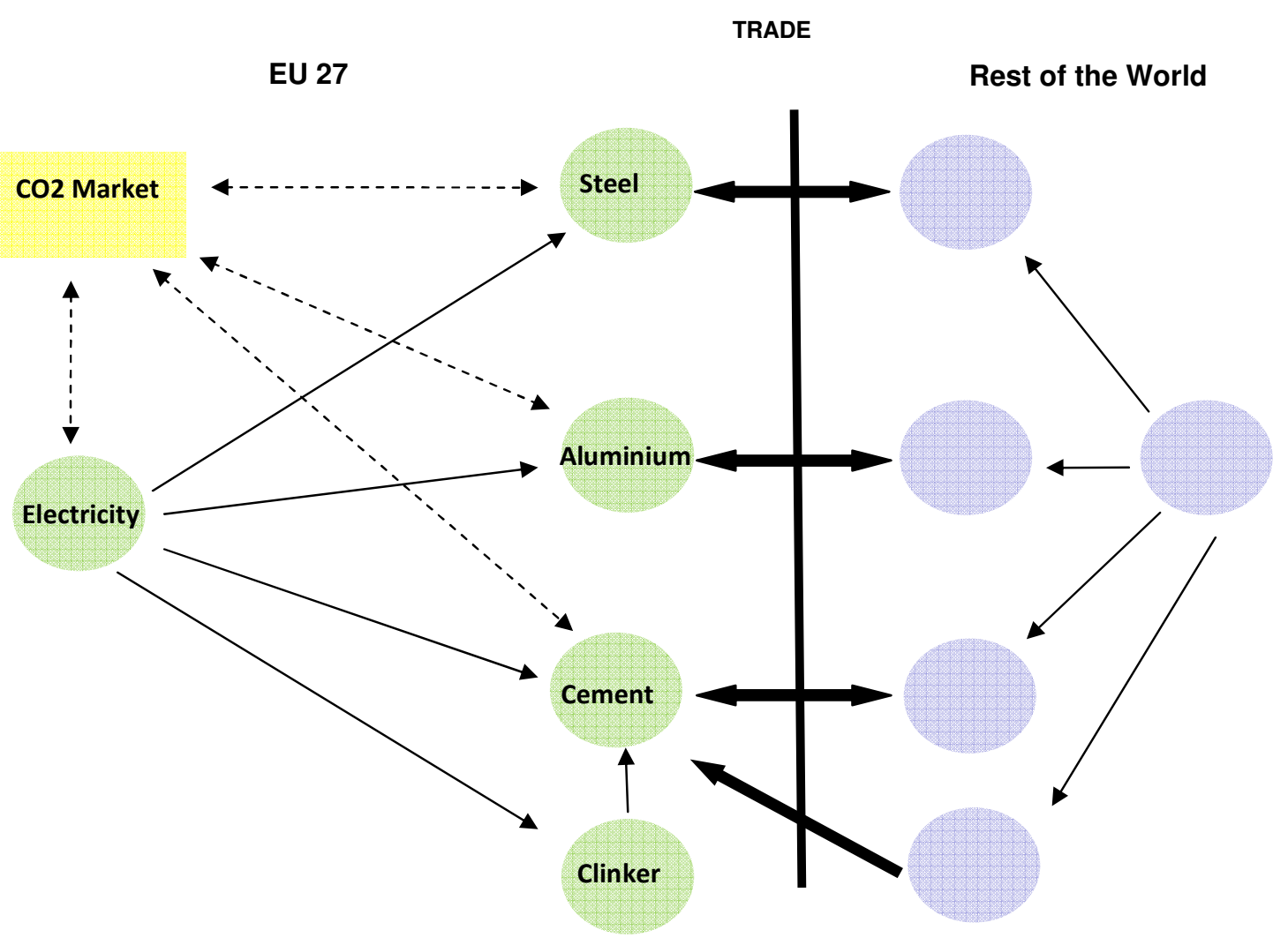

\section{Consumption}

The model comprises two regions: the European Union 27 (EU) and the rest of the world (RoW). In each region $r=\{E U, R o W\}$, the representative consumer is assumed to have a two-tier utility function. The upper tier is a (logged) Cobb-Douglas function of the utility derived from consuming the goods produced by each industry, giving rise to fixed expenditures shares $\left(\alpha_{r}^{i}\right)$ out of income $\left(Y_{r}\right)$ :

$$
U_{r}=\sum_{i=\{C, A, S, E\}} a_{r}^{i} \cdot \ln \left(u_{r}^{i}\right)+\left(1-\sum_{i=\{C, A, S, E\}} a_{r}^{i}\right) \cdot \ln \left(Z_{r}\right)
$$

\footnotetext{
${ }^{16}$ CASE II is an evolution of the CASE model (Demailly and Quirion, 2008). Among the differences between the two versions, CASE II models an imperfect competition in the cement, aluminium and steel sectors, the aluminium sector is included in the EU ETS and the cement sector is more detailed.

${ }^{17}$ In fact, PFC emissions from the aluminium sector are covered as well but $\mathrm{CO}_{2}$ market and $\mathrm{CO}_{2}$ price are the usual terms.
} 
where $\alpha_{r}^{i}$ is the expenditure share of region $r$ in industry $i, u_{r}^{i}$ is the sub-utility from consumption of the varieties produced in the industry $i$ and $Z_{r}$ represents the consumption level of the numéraire good. Indexes $C, A, S$ and $E$ represent respectively cement, aluminium, steel and electricity.

Expenditures in region $r$ in goods produced by industry $i$ are then $\alpha_{r}^{i} Y_{r}$. We assume that the expenditure parameters stay constant between 2006 (year used to calibrate the model) and 2020 (year used for the simulations of the business as usual and the different climate policies). GDP $Y_{r}$ is exogenous and growing. ${ }^{18}$

In turning to the lower-tier of the utility function, we examine expenditures allocation in the industries $C, A$ and $S$, each consisting of a domestic variety and a foreign variety. ${ }^{19}$ The sub-utility $u_{r}^{i}$ is a constant elasticity substitution (CES) aggregate of the two varieties. The representative consumer has different preferences over varieties (noted $p r e f_{r r}^{i}$ for the domestic variety and $p r e f_{r r}^{i}$ for the imported one) depending on their places of production, allowing in particular for home bias. The subutility function is then:

$$
u_{r}^{i}=\left(\left(\operatorname{pref}_{r r}^{i} \cdot Q_{r r}^{i}\right)^{\left(\sigma_{i}-1\right) / \sigma_{i}}+\left(\operatorname{pref}_{r r^{\prime}}^{i} \cdot Q_{r r^{\prime}}^{i}\right)^{\left(\sigma_{i}-1\right) / \sigma_{i}}\right)^{\sigma_{i} /\left(\sigma_{i}-1\right)}
$$

where $r$ and $r^{\prime}=\{E U, R o W\}, r^{\prime} \neq r, i=\{C, A, S\}, Q_{r r}^{i}$ (resp. $Q_{r r^{\prime}}^{i}$ ) is the consumption level in region $r$ of the good produced by industry $i$ in region $r$ (resp. $r^{\prime}$ ) and $\sigma_{i}$ represents the elasticity of substitution (the Armington elasticity) between domestic and foreign varieties in industry $i$.

Maximising this sub-utility function subject to expenditures and the delivered prices from the two possible product origins, we obtain the demand curves:

$$
\begin{aligned}
& Q_{r r}^{i}=\alpha_{r}^{i} \cdot Y_{r} \frac{\left(\text { pref }_{r r}^{i}\right)^{\sigma_{i}-1} \cdot\left(p_{r r}^{i}\right)^{-\sigma_{i}}}{\left(p_{e f} f_{r r}^{i}\right)^{\sigma_{i}-1} \cdot\left(p_{r r}^{i}\right)^{1-\sigma_{i}}+\left(\text { pref }_{r r^{\prime}}^{i}\right)^{\sigma_{i}-1} \cdot\left(p_{r r^{\prime}}^{i}\right)^{1-\sigma_{i}}} \\
& Q_{r r^{\prime}}^{i}=\alpha_{r}^{i} \cdot Y_{r} \frac{\left(p r e f_{r r^{\prime}}^{i}\right)^{\sigma_{i}-1} \cdot\left(p_{r r^{\prime}}^{i}\right)^{-\sigma_{i}}}{\left(\operatorname{pref}_{r r}^{i}\right)^{\sigma_{i}-1} \cdot\left(p_{r r}^{i}\right)^{1-\sigma_{i}}+\left(\operatorname{pref}_{r r^{\prime}}^{i}\right)^{\sigma_{i}-1} \cdot\left(p_{r r^{\prime}}^{i}\right)^{1-\sigma_{i}}}
\end{aligned}
$$

where $p_{r r}^{i}$ and $p_{r r^{\prime}}^{i}$ are the delivered prices respectively of the domestic and of the foreign variety of the industry $i$ faced by the consumers of the region $r$.

For electricity, we do not account for international trade since it is negligible at the EU level. The electricity demand in region $r$ is then the sum of the demand from the cement, aluminium and steel firms localised in region $r$ and of a fixed expenditure share out of income $\alpha_{r}^{E} \cdot Y_{r}$ from the representative consumer.

\section{Supply}

The CES specification of the representative consumer's utility has mostly been used in monopolistic competition models following Dixit and Stiglitz (1977) and Krugman (1980) where firms do not take into account the effect of their behaviour on other firms. Strategic interactions are therefore

\footnotetext{
${ }^{18}$ See Monjon and Quirion (2011) for the assumptions on exogenous data.

${ }^{19}$ We assume that all domestic varieties are perfect substitutes for each other, as are all foreign varieties, but that domestic and foreign varieties are incomplete substitutes.
} 
neglected, which is not very relevant for the industries analysed. We explore the case where firms compete in quantities, as in a standard Cournot oligopoly.

In the cement, aluminium and steel sectors, each firm sells in both regions. In each region, there are $n_{r}^{i}$ domestic firms in competition. Firms are in competition regionally and, less intensively, internationally. Trade between the regions entails a constant per-unit transportation cost. Then the profit function of a firm localised in region $r$ is:

$$
\pi_{r}^{i}=\left(p_{r r}^{i}-m c_{r}^{i}\right) \cdot q_{r r}^{i}+\left(p_{r^{\prime} r}^{i}-m c_{r}^{i}-t c_{r^{\prime} r}^{i}\right) \cdot q_{r^{\prime} r}^{i}-F C_{r}^{i}
$$

where $r$ and $r^{\prime}=\{E U, R o W\}$ and $r^{\prime} \neq r, i=\{C, A, S\}, \quad p_{r r}^{i}$ and $p_{r^{\prime} r}^{i}$ are the delivered prices of the good produced by a firm of industry $i$ localised in region $r$ and sold, respectively, in region $r$ and in region $r^{\prime}, m c_{r}^{i}$ (resp. $F C_{r}^{i}$ ) the marginal (resp. fixed) production cost of firms localised in region $r, q_{r r}^{i}$ (resp. $q_{r^{\prime} r}^{i}$ ) the quantity sold in the domestic market (resp. in the foreign market) and $t c_{r^{\prime} r}^{i}$ the (unit) transportation cost from region $r$ to region $r^{\prime}$.

This framework allows firms to set different prices in each market. This contrasts with the DixitHelpman-Krugman model in which firms perceive the same elasticity of demand in each market and therefore set export prices (net of transport costs) equal to their domestic prices (Head and Ries, 2001).

To determine the number of firms in each region, we assume that free-entry entails zero profit in both regions. At the equilibrium, all firms from the same region being symmetric, we have $Q_{r r}^{i}=n_{r}^{i} \cdot q_{r r}^{i}$ (resp. $\left.Q_{r^{\prime} r}^{i}=n_{r}^{i} \cdot q_{r^{\prime} r}^{i}\right)$.

Excluding expenditures related to the climate policy, production costs (variable and fixed) are assumed constant but differ across regions.

\section{Assumptions about the sectors}

The risk of carbon leakage seems to be the highest for semi-finished products (Hourcade et al., 2007). Consequently, the model focuses on this stage of the production chain.

For the steel sector, we represent semi-finished products (e.g. slabs), because they feature higher $\mathrm{CO}_{2}$ /turnover and $\mathrm{CO}_{2}$ /value added ratios than finished products, hence the risk of leakage is higher than in finished products. We aggregate long and flat products and both production routes (basic oxygen furnace and electric arc furnace).

The aluminium sector only covers primary aluminium, international trade occurring mainly at this stage of transformation. Aluminium has been treated in a specific way in the model because Iceland and Norway participate in the EU ETS since 2008 and these two countries account for almost half aluminium exports to the EU 27 (Reinaud, 2008). ${ }^{20}$ Consequently the model includes Iceland's and Norway's aluminium sector in the EU ETS.

In the cement sector, we consider that in the EU, cement may be imported as a finished product, or in the form of clinker which must be milled and blended into cement at the point of arrival. We assume out clinker exports from the EU to the RoW since they are already negligible absent climate policy. For the $\mathrm{EU}$, we take into account substitution between clinker (the $\mathrm{CO}_{2}$-intensive intermediate product) and $\mathrm{CO}_{2}$-free substitutes (e.g. fly ashes or blast furnace slag) as well as substitution between domestic and imported clinker. The proportion of clinker used to produce cement in the EU, $S h^{c K}$,

\footnotetext{
${ }^{20}$ According to the UN COMTRADE database, in 2006, cement and steel exports from Iceland and Norway to the EU 27 represent respectively around $0.4 \%$ and $1 \%$ of EU imports, while cement and steel exports from EU 27 to Iceland and Norway account around $6 \%$ and $3 \%$ of EU exports respectively.
} 
and the market share of imported clinker in the EU, $S h_{E U, R o W}^{C K}$, are modelled through nested Logit functions ${ }^{21}$ :

$$
S h^{C K}=\frac{\left(T C_{E U}^{C K}\right)^{-\eta 1}}{\left(T C_{E U}^{C K}\right)^{-\eta 1}+\left(T C_{E U}^{S U B}\right)^{-\eta 1}} \quad S h_{E U, R o W}^{C K}=\frac{\left(T C_{E U, R o W}^{C K}\right)^{-\eta 2}}{\left(T C_{E U, E U}^{C K}\right)^{-\eta 2}+\left(T C_{E U, R o W}^{C K}\right)^{-\eta 2}}
$$

Where $T C_{E U}^{C K}=S h_{E U, R o W}^{C K} \cdot T C_{E U, R o W}^{C K}+\left(1-S h_{E U, R o W}^{C K}\right) \cdot T C_{E U, E U}^{C K}$

$T C_{E U}^{C K}$ and $T C_{E U}^{S U B}$ represent, respectively, the total cost of using clinker and of using $\mathrm{CO}_{2}$-free substitutes (flying ashes, blast furnace slag...) in $\mathrm{EU}$ cement production, $T C_{E U, E U}^{C K}$ and $T C_{E U, R o W}^{C K}$ represent, respectively, the cost of using domestic and imported clinker to produce cement in the EU while $\eta 1$ and $\eta 2$ are positive parameters representing the responsiveness of $S h^{C K}$ and $S h_{E U, R o w}^{C K}$ to the changes in relative costs.

The Logit functional form conserves physical quantities, which is a great advantage over a CES function since we want to represent physical quantities of cement. In the Logit function representing the choice between clinker (either imported or domestic) and substitutes, the parameters are calibrated to represent the share of substitutes in cement in 2006 (23\%) and an ad hoc assumption that a doubling of the clinker cost, other things equal, would entail a doubling of the share of substitutes in cement. In the Logit function representing the choice between domestic or imported clinker, the parameters are calibrated to represent the share of imported clinker in 2006 (6\%) and to fit the following result from GEO-CEMSIM, a detailed geographic model of the global cement industry featuring transportation costs and capacity constraints: with a $\mathrm{CO}_{2}$ price of $€ 20$, the share of imported clinker doubles (Demailly and Quirion, 2006).

\footnotetext{
${ }^{21}$ Such functions are used in hybrid energy-economy models such as CIMS (Murphy et al., 2007) and IMCALIM-R (Crassous et al., 2006).
} 


\section{References for the Appendix}

Crassous, R., Hourcade, J.-C., Sassi, O., 2006. Endogenous structural change and climate targets: modeling experiments with Imaclim-R. Energy Journal Special Issue \#1 Endogenous Technological Change, 259-276

Demailly, D. and P. Quirion, 2006. $\mathrm{CO}_{2}$ abatement, competitiveness and leakage in the European cement industry under the EU ETS: grandfathering vs. output-based allocation, Climate Policy, 6(1), August 2006, pp. 93-113.

Demailly, D. and P. Quirion, 2008. Concilier compétitivité industrielle et politique climatique : faut-il distribuer les quotas de $\mathrm{CO} 2$ en fonction de la production ou bien les ajuster aux frontières ?. La Revue Economique, vol. 59, N³, mai 2008, pp. 497-504.

Dixit, A. and J. E. Stiglitz, 1977. Monopolistic Competition and Optimum Product Diversity. American Economic Review, 67(3), 297-308.

Krugman P., 1980. Scale Economies, Product Differentiation, and the Pattern of Trade. The American Economic Review, 70(5), 950-959.

Head, K. and J. Ries, 2001. Increasing Returns Versus National Product Differentiation as an Explanation for the Pattern of US-Canada Trade. American Economic Review, 91(3), 858-876.

Hourcade, J.-C., D. Demailly, K. Neuhoff and M. Sato, 2007. Differentiation and dynamics of EU ETS competitiveness impacts. Climate Strategies report.

Fischer, C. and A. Fox, 2009. Comparing Policies to Combat Emissions Leakage: Border Tax Adjustments versus Rebates. Resources for the future Discussion paper 09-02.

Monjon, S. and P. Quirion, 2011. Addressing leakage in the EU ETS: Border adjustment or outputbased allocation? Ecological Economics, forthcoming, doi:10.1016/j.ecolecon.2011.04.020

Murphy, R., N. Rivers and M. Jaccard, 2007. Hybrid modeling of industrial energy consumption and greenhouse gas emissions with an application to Canada. Energy Economics, 9(4): 826-846

Reinaud, J., 2008. Climate policy and carbon leakage - Impacts of the European Emissions Trading Schemes on aluminium. International Energy Agency, October.

Weyant, J. P., F. C. de la Chesnaye and G. J. Blanford (eds), 2006. Multi-Greenhouse Gas Mitigation and Climate Policy Special Issue. The Energy Journal. 